\title{
New Utilization of Specific Biomass: Lignin in the Iron Ore Sintering Process
}

\author{
Róbert Findorák ${ }^{1, *}$, Jaroslav Legemza ${ }^{1}$, Mária Fröhlichová ${ }^{1}$, Gabriela Fabriciová ${ }^{2}$ and \\ Martina Džupková ${ }^{1}$ \\ 1 Faculty of Materials, Metallurgy and Recycling, Technical University of Kosice, Letná 9, 04200 Košice, \\ Slovakia; jaroslav.legemza@tuke.sk (J.L.); maria.frohlichova@tuke.sk (M.F.); \\ martina.dzupkova@tuke.sk (M.D.) \\ 2 Department of Biophysics, University of Pavol Jozef Safarik Kosice, Jesenna 5, 04154 Kosice, Slovakia; \\ gabriela.fabriciova@upjs.sk \\ * Correspondence: robert.findorak@tuke.sk; Tel.: +421-55-602-3155
}

Received: 11 August 2020; Accepted: 27 August 2020; Published: 31 August 2020

\begin{abstract}
The use of lignin can be one of the methods of coke powder substitution in the agglomeration process. This article specifies the material research of lignin and the technological and ecological parameters of the agglomeration process in laboratory conditions using biomass lignin. The methodology of the Raman and infrared spectroscopy, representing a new approach in the analysis and assessment for the purposes of material characteristics for the agglomeration process, was applied to study the structure of carbonaceous matter. The material research of lignin has determined that its calorific value corresponds to ca. $80 \%$ of the calorific value of coke powder, while its reactivity is higher than that of the coke. Although the substitution of coke powder using different types of waste biomass (e.g., wood sawdust) in the production of the agglomerate is limited to the maximum of $8-15 \%$, in case of lignin, more than $20 \%$ can be substituted, while the standard properties of the produced agglomerate are maintained. The lower emissions of sulfur and nitrogen oxides as well as the reduction of carbon footprint in the agglomeration process as a result of the so-called zero $\mathrm{CO}_{2}$ balance in the formation and processing of the biomass represent its positive aspects. Based on the laboratory research of lignin, up to a $50 \%$ substitution of coke powder with this type of biomass can be predicted for the technology of agglomerate production in real operation.
\end{abstract}

Keywords: agglomerate; sintering; carbon fuel; coke breeze; biomass; lignin; production; emissions

\section{Introduction}

Both current and historical trends of the global steel production indicate growth, consequently raising questions in connection with the extraction of primary sources, processing of secondary raw materials, energy potential, and the utilization of alternative fuels to streamline and optimize the production process. In addition to the economy, the environmental impact will also be the common denominator in the pursuit of new directions in the production of steel. This very indicator appears to be the key issue also for the future direction and changes in the technology of iron and steel production, which is immediately related to the technology of agglomerate production. In this context, enormous efforts have been made in recent years to search for the most appropriate methods to reduce or totally substitute the energy of fossil fuels in the area of agglomerate production as well. It is expected that low carbon sources will cover more than half of the generated energy in 2040, while solar photovoltaics, wind, and water energy should play a leading role. Certain progress is anticipated also in the utilization of biomass as an alternative source of renewable energy and its application in the metallurgical industry as well. The research and application of biomass in the production of agglomerate have been taking 
place in the world for approximately 15 years. It has resulted in research studies covering mainly the use of biomass in the laboratory conditions, even though parameters for the operational application of biomass on industrial sintering belts have already been predicted. The technology of agglomerate production has gone through many innovations since its creation, and the progress in the field of mitigating the negative impact on the environment is increasingly coming to the forefront. Its main mission is to reduce the $\mathrm{CO}_{2}$ emissions and thus to mitigate the emission burden of $\mathrm{CO}_{2}$ on the atmosphere. Therefore, the issue of determining the required amount and type of carbonaceous fuel for the production of Fe agglomerate is crucial. The change in the quantity of fuel in an agglomeration mixture alters almost all technological and qualitative indicators of agglomerate production. Fuel has a critical impact on temperature and oxidation-reduction conditions in an agglomeration charge. Figure 1 shows a diagram of sintering on a sintering belt, illustrating a layer of agglomeration charge traveling horizontally on a pallet grate after its ignition, while air is sucked through it vertically from top to bottom. The combustion of coke (or other carbonaceous fuel) present in the agglomeration charge is affected by the sucked air. Here, we can see the course and change in temperature along the height of the sintered layer, the so-called combustion zone, and its front, where the maximum temperatures reach $1350-1400{ }^{\circ} \mathrm{C}$. The diagram also shows some modern intensification features, resulting from research and development projects in recent years that have been implemented in the best industrial companies in the world (e.g., flue gas recycling, enriching of air with oxygen for burner systems, desulfurization of flue gas, etc.).

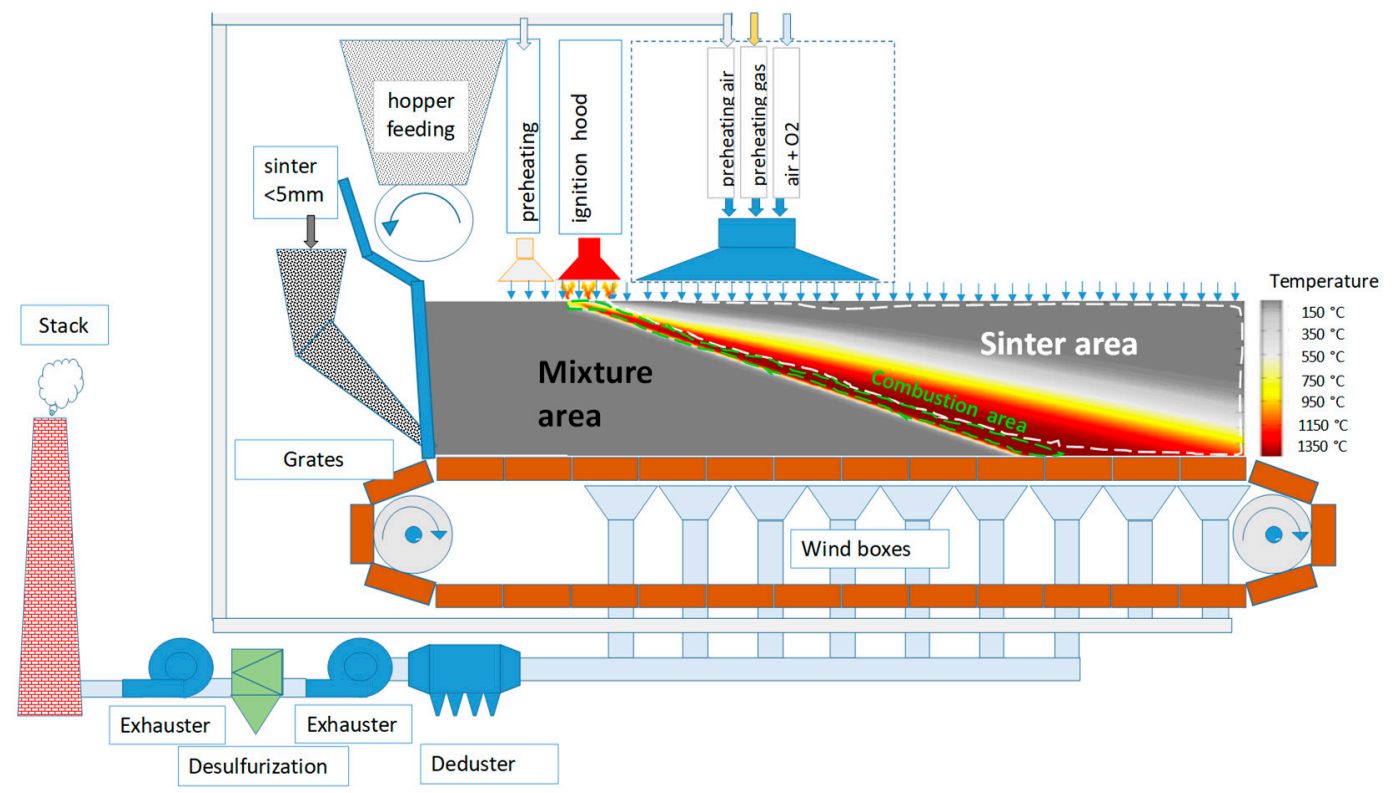

Figure 1. Diagram of sintering on a sintering belt [1].

Research papers that are focused on a complex solution to the energy and environmental needs analyze in detail the impact parameters of individual factors, taking into account compliance with the requirements for the quality of agglomerate. The control and optimization of the process through all technological nodes can be provided by the control of the process using advanced mathematical models, such as a Simetal CIS Sinter Vairon control system, which can be implemented in the existing facilities as well [2]. The research paper [3] dealing with the reduction of emissions proved the feasibility of $\mathrm{NO}_{\mathrm{X}}$ reduction by the management and control of combustion in the sintering process. The control of sucked air negative pressure can affect not only the amount of particulate matter but also the quality of the produced agglomerate. The optimization of the pelletizing process is another possible solution for increasing the performance parameters and ultimately achieving the savings. It includes a pre-pelletization of a homogenized mixture to the desired permeability and moisture. The increase in productivity of sintering through parameters of a sintering facility is facilitated by the very change in 
the belt geometry, which means considerable financial costs in the existing operations. The adjustment of geometry does not have to comprise only the increase in the sintering box surface, but also the modification of the sintered layer height. However, this change requires solutions to ensure sufficient permeability and negative pressure. A selective charging system (Twin-Layer Charging System) is one of the solutions. It provides the laying of more coarse-grained fractions on a sintered bed with a lower fuel content, while the upper layers consist of more fine-grained fractions of the agglomeration charge with a higher fuel content. Besides enhancing the productivity, this technological feature contributes to improving the quality of agglomerate, decreasing the fuel consumption, and reducing the $\mathrm{CO}_{2}$ emissions [2].

In the present research in the field of fuel, those studies addressing the agglomeration charge are focused on the possibilities of utilizing certain types of biomass as a partial substitution of coke powder. The specific results of research task solutions in the world prove that the substitution of coke powder with biomass (wood sawdust, sunflower husks, shells of almonds and nuts, etc.) in the agglomeration process is limited to the level of ca. $8-20 \%$. With such replacement, using certain types of biomass, emissions of carbon, nitrogen, and sulfur oxides are reduced by $5-40 \%$. Optimistic projections for the employment of these energy sources, falling into the family of so-called green energy sources with a low environmental impact, are also suggested by the results of this laboratory research, where temperature profiles of combustion mechanisms, performance parameters, and emission profiles were determined [4-10]. Technical hydrolyzed lignin, which is a by-product of ethanol production using the distillation of wood, can be included among the prospective types of biomass. Over time, the industrial production of ethanol turned out to be highly energy-intensive and was terminated, leaving only huge dumps of wood waste, which might be used in the production of pellets and consequently as a substitution for a part of coke powder in the production of the agglomerate. The paper [11] specified that lignin had a lower calorific value than coke powder, yet this value was higher than the calorific value of sawdust. Lignin has a significantly lower ash content, lower melting point, and lower nitrogen and sulfur content than coke. These are the parameters predicting its prospective utilization in the agglomeration process as well. In the paper [12], a thermodynamic study of coke powder and lignin combustion was carried out as a part of the mathematical modeling with the creation of thermodynamic models on the basis of the actual fuel composition. The majority of the mineralogical phases formed at the temperatures of lignin burning include quartz $\left(\mathrm{SiO}_{2}\right)$, oligoclase $\left(\mathrm{CaAl}_{2} \mathrm{Si}_{2} \mathrm{O}_{8}\right)$, and calcite $\left(\mathrm{CaCO}_{3}\right)$. These phases were identified in the X-ray diffraction as well [11]. Thermal stress experiments using thermovision observations of samples were also carried out to study the burning of lignin [13]. The methodology of thermovision monitoring during the thermal stress may contribute to clarifying the behavior of tested types of biomass (as well as synthetically prepared mixed fuels) in various heating conditions (temperature, atmosphere, and the like). Online monitoring of biomass combustion is a part of this methodology, where different properties affecting the combustion process (composition, granulometry, porosity, moisture, a.o.) are monitored. Based on the experiments carried out for the combustion of lignin pellets in the sintering layer conditions, it can be stated that the substitution of coke powder with granulometrically modified pellets is feasible. The lignin pellets burn more intensively in the whole range of applicable grain sizes compared to sinter coke. With regard to the comparison of lignin combustion at various grain sizes, the optimum parameters (the highest temperature and short time) were achieved for the lignin, with the average grain size of $\mathrm{D}_{\mathrm{avg}}=1.93 \mathrm{~mm}(\mathrm{LA} 3)$, as shown in Figure 2, corresponds approximately to the grain size of coke powder $\left(D_{\text {avg }}=1.55 \mathrm{~mm}\right)$. 


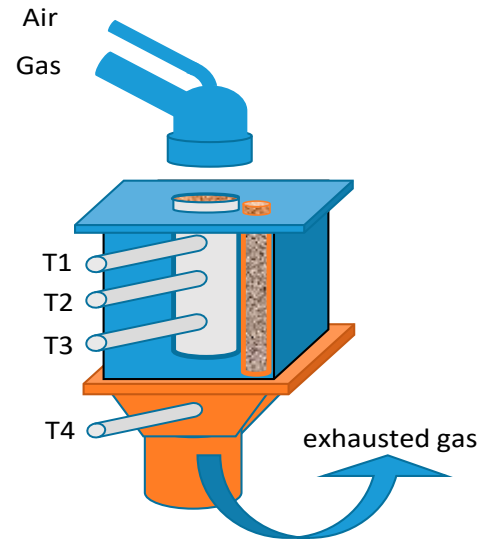

(a)

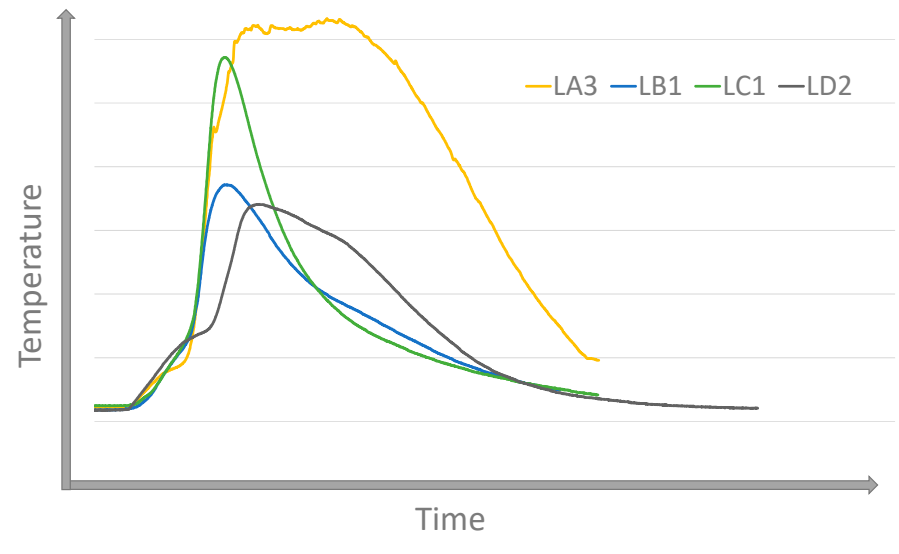

(b)

Figure 2. Illustration of lignin combustion with different mean diameters ( $\left.D_{a v g}\right)$ : (a) experimental plan, (b) temperature profile of samples on the position T2. (T1, T2, T3-temperature in sintered layer, T4-flue gas temperatures, LA3 - Davg $=1.93 \mathrm{~mm}, \mathrm{LB} 1-\mathrm{D}_{\mathrm{avg}}=4.08 \mathrm{~mm}, \mathrm{LC} 1-\mathrm{D}_{\text {avg }}=6.5 \mathrm{~mm}$, LD2 $-\mathrm{D}_{\mathrm{avg}}=1.05 \mathrm{~mm}$ ).

The combustion zone was observed in the laboratory production of agglomerate using lignin. It follows that lignin burns faster than coke powder, and the combustion zone in the sintered layer is considerably wider with the higher substitution of lignin for coke due to the higher porosity and reactivity of lignin, as shown in Figure 3. The speed of the thermal layer movement is given by Equation (1) [14]:

$$
V_{t v}=K \times \frac{C_{g}}{C_{v s}} \times \omega_{0},
$$

where $V_{t v}$-speed of thermal layer movement $(\mathrm{mm} / \mathrm{min}) ; K$-proportionality factor; $C_{g}$-specific heat capacity of gas $\left(\mathrm{kJ} / \mathrm{m}^{3} \cdot \mathrm{K}\right) ; C_{v s}$-apparent volume heat capacity of sinter mixture $\left(\mathrm{kJ} / \mathrm{m}^{3} \cdot \mathrm{K}\right) ; \omega_{0}$-air suction speed through the layer $(\mathrm{mm} / \mathrm{min})$.
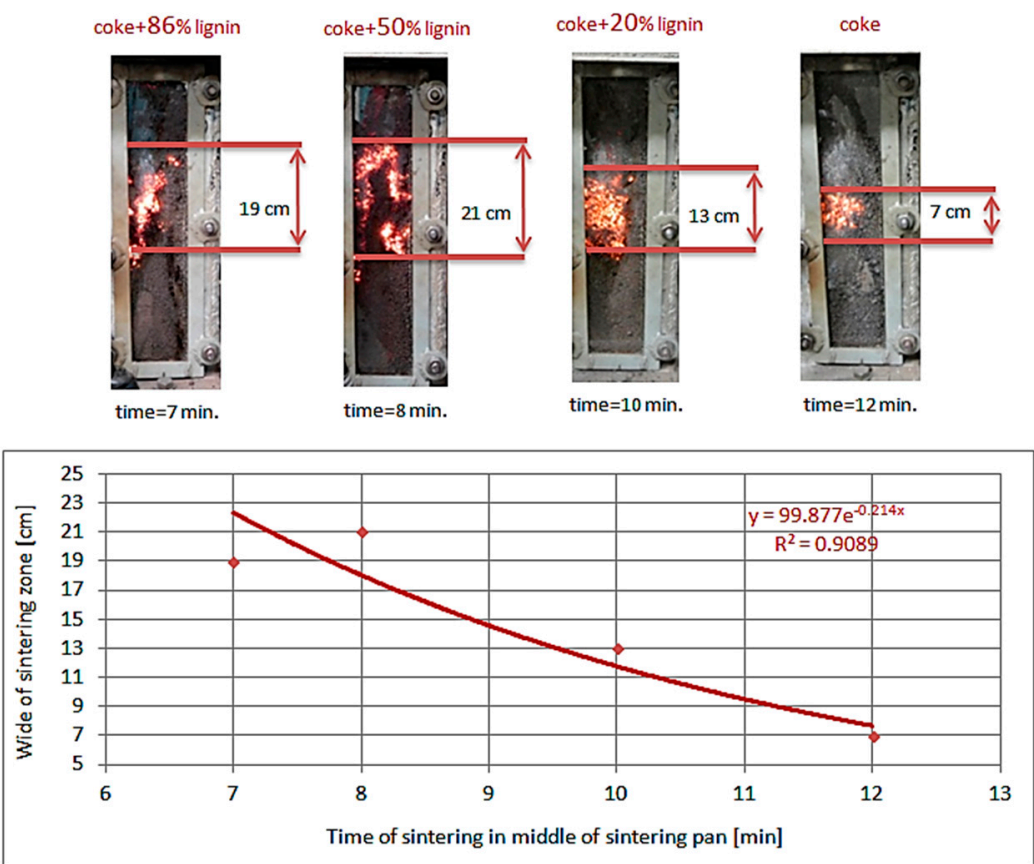

Figure 3. Characteristics of the sintering zone in the production of agglomerates using coke and lignin. 


\section{Materials and Methods}

The selection and use of a particular biomass type was based on perfect knowledge of the technological process for which the selection was being made, as well as the in-depth analysis of a material and its detailed specifications. The biomass called "technical hydrolyzed lignin" which is a by-product of ethanol production by wood distillation was selected with an emphasis on the above. This industrial production of ethanol proved to be highly energy-intensive over time and was discontinued, leaving only huge landfills for wood waste. Biomass pellets were produced from the above material at the Bionet plant in Onege, Russia. From the physical and chemical perspective, the technical hydrolyzed lignin (hereinafter the "lignin" or "LIG"), as shown in Figure 4, is a brown finely dispersed material with the grain size of 0.5 to $25.0 \mathrm{~mm}$. The moisture of the raw material (lignin) in a pile is ca. $65-67 \%$. The bulk density is $930-1000 \mathrm{~kg} / \mathrm{m}^{3}$, and the ash content is $1-9 \%$. Biomass pellets were made from the above material, as shown in Figure $4 \mathrm{a}$. The produced $12.3 \mathrm{~mm}$ long pellets with a diameter of $8 \mathrm{~mm}$ had the bulk density of $750 \mathrm{~kg} / \mathrm{m}^{3}$. The lignin pellets (LIG) were disintegrated from the original size, while the fractions of 1-3.15 mm were used for the agglomeration process after the disintegration, as shown in Figure $4 \mathrm{~b}$.

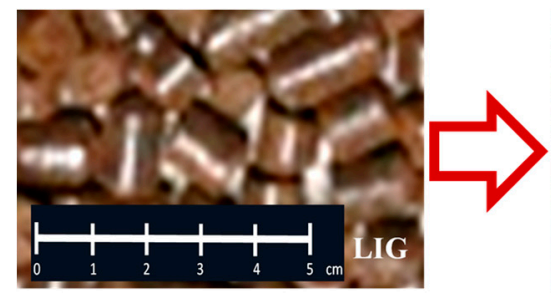

(a)

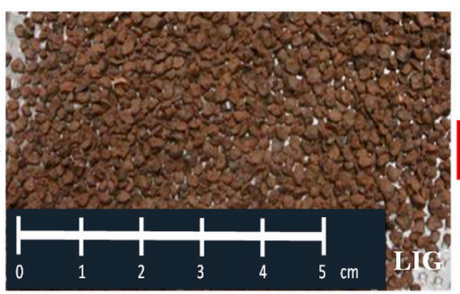

(b)

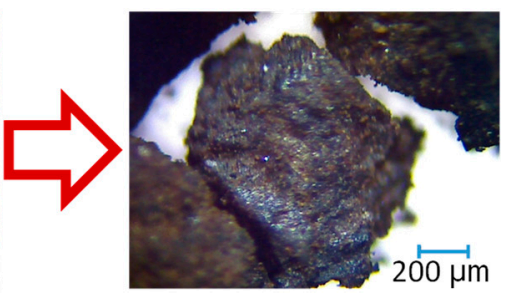

(c)

Figure 4. Illustration of selected biomass, lignin, for the agglomeration process: (a) lignin pellets, (b) after disintegration, (c) macro-photo of lignin.

The characteristics and the analysis of lignin included structural analysis, an analysis of chemical and phase composition of lignin and lignin ash, as well as physical properties of fuels (calorific value, higher calorific values, and melting point of ash). The analyses were performed in a certified laboratory using standard analytical methods (STN ISO 1171, STN 441359, STN ISO 562, STN ISO 1928). The chemical analysis and the energy capacity of the disintegrated pellets are listed in Table 1 together with the analysis of standard fuel, i.e., the agglomeration coke. The examined lignin pellets contain $3.4 \%$ of ash, which is less than one-third ( $28 \%$ ) compared to coke $(12.1 \%)$. The main difference against coke is in the content of volatile combustible and the moisture. The mutual ratio of elements $C, H, N, S$, and $\mathrm{O}$ also corresponds to the energy potential and the determined calorific value of both samples. For example, the energy potential of lignin pellets is somewhat higher compared to the wood biomass (wood sawdust). Additional details regarding the material research of lignin are presented in another article of the authors [11].

Table 1. Chemical analysis and energy content of fuels [12].

\begin{tabular}{ccccccccccc}
\hline Fuel & \multicolumn{4}{c}{ Proximate Analysis (wt\%) } & \multicolumn{5}{c}{ Ultimate Analysis (wt\%) } \\
\hline & $\begin{array}{c}\mathbf{H}_{\mathbf{2}} \mathbf{O} \\
(\mathbf{W})\end{array}$ & $\begin{array}{c}\text { Ash } \\
(\mathbf{A})\end{array}$ & $\begin{array}{c}\text { Volatile } \\
\mathbf{( C V )}\end{array}$ & $\begin{array}{c}\text { Fixed Carbon } \\
\left(\mathbf{C}_{\text {FIX) }}\right)\end{array}$ & $\mathbf{C}$ & $\mathbf{H}$ & $\mathbf{O}$ & $\mathbf{N}$ & $\mathbf{S}$ & $\begin{array}{c}\text { Caloric Value } \\
(\mathbf{M J} / \mathbf{k g})\end{array}$ \\
\hline Coke dust & 5.5 & 12.10 & 1.50 & 80.9 & 85.4 & 0.30 & 0.60 & 1.30 & 0.30 & 28.16 \\
Lignin & 8.6 & 3.4 & 67.90 & 20.1 & 62.9 & 5.75 & 27.60 & 0.2 & 0.15 & 23.14 \\
\hline
\end{tabular}

For mathematical modeling, the basic chemical reactions with standard Gibbs energy and mass and thermal balance were calculated. Thermodynamic data were obtained from the software HSC Chemistry (Outokumpu Research Oy, Pori, Finland, 2018). The experiments were carried out in a laboratory sintering pan (Technical University of Košice, Košice, Slovakia), as shown in Figure 5. 


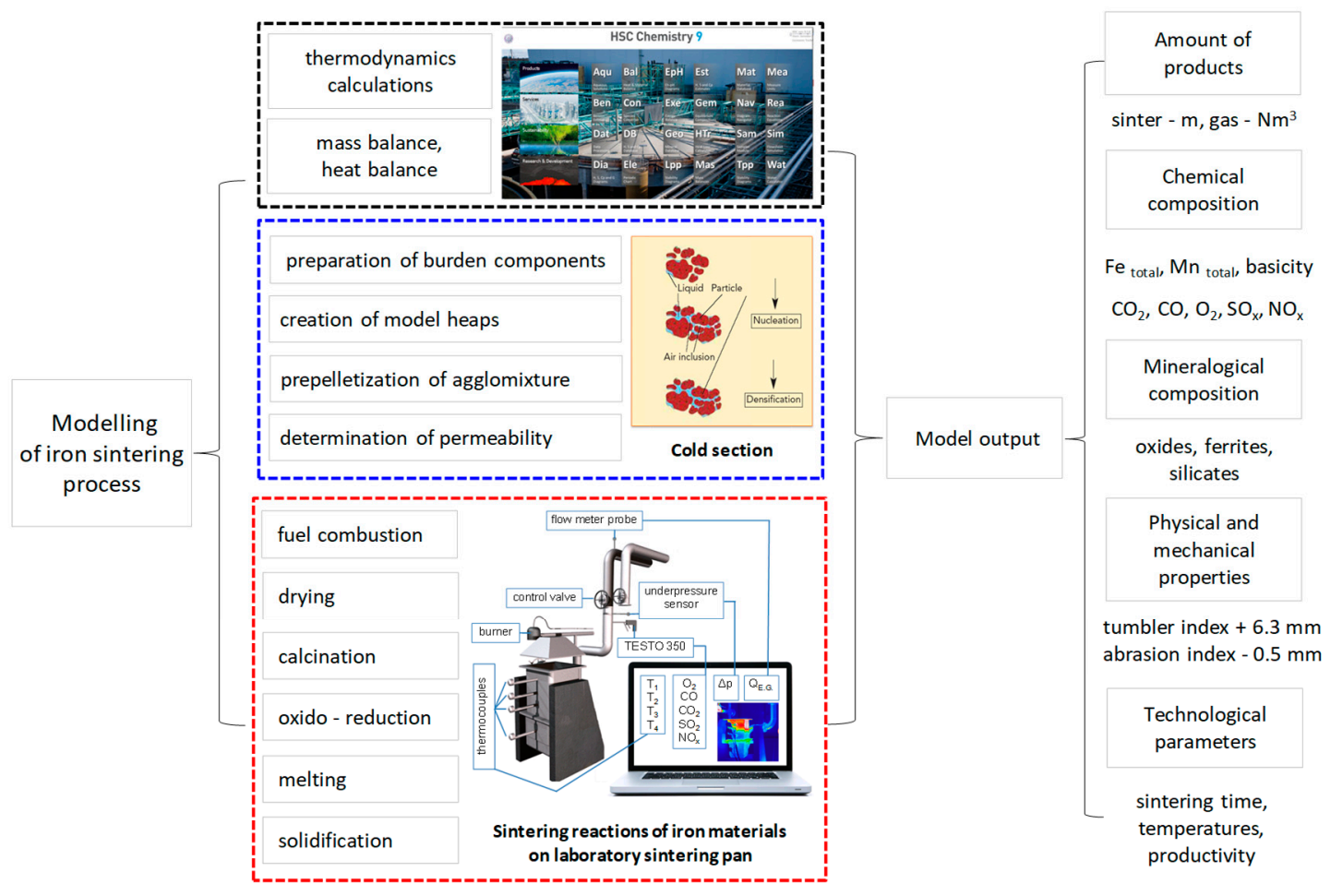

Figure 5. Scheme presenting the global method with modeling of the iron sintering process.

For the high-temperature range in the sintered layer, three thermocouples of the PtRh10-Pt type were used. The flue gas temperature was read at two levels by an $\mathrm{NiCr}-\mathrm{Ni}$ type thermocouple. The chemical composition and temperature of the flue gas were analyzed by a TESTO 350 device (Testo SE \& Co. KGaA, Lenzkirch, Germany). The differential pressure was measured by an Itabar type probe (Intra-Automation $\mathrm{GmbH}$, Grevenbroich, Germany). Laboratory experiments on the laboratory sintering pan were performed using ferriferous raw materials: aggloore Ukraine (content of $\mathrm{Fe}_{\mathrm{TOT}}=60.39 \%$ ) and concentrate Ukraine (content of $\mathrm{Fe}_{\mathrm{TOT}}=67.95 \%$ ), Table 2. The concentrate/iron ore ratio in the mixtures was 1:1. The other mixture components (dolomite, calcite, lime) had a commercial standard chemical composition. These inputs were included in prepared agglomeration mixtures with basicity within the interval of 1.7-1.8.

Table 2. Chemical analysis of Fe materials [12].

\begin{tabular}{|c|c|c|c|c|c|c|c|c|c|c|}
\hline Iron material & $\begin{array}{l}\text { Humidity } \\
(\%)\end{array}$ & $\mathrm{Fe}$ & $\mathrm{FeO}$ & $\mathrm{Fe}_{2} \mathrm{O}_{3}$ & $\mathrm{SiO}_{2}$ & $\begin{array}{l}\mathrm{Al}_{2} \mathrm{O}_{3} \\
(w \mathrm{t} \%)\end{array}$ & $\mathrm{CaO}$ & $\mathrm{MgO}$ & Mn & $\mathbf{P}$ \\
\hline Ore & 4.20 & 60.39 & 0.52 & 85.38 & 11.07 & 0.90 & 0.07 & 0.21 & 0.027 & 0.028 \\
\hline Concentrate & 9.79 & 67.95 & 27.80 & 66.16 & 4.89 & 0.16 & 0.12 & 0.24 & 0.030 & 0.011 \\
\hline Iron material & $\begin{array}{c}\text { Basicity } \\
(-)\end{array}$ & $S$ & $\mathrm{Na}_{2} \mathrm{O}$ & $\mathrm{K}_{2} \mathrm{O}$ & $\mathrm{TiO}_{2}$ & $\begin{array}{c}\mathrm{Pb} \\
(\mathrm{wt} \%)\end{array}$ & $\mathrm{Zn}$ & As & $\mathrm{Cl}$ & $\mathrm{C}$ \\
\hline Ore & 0.024 & 0.015 & 0.154 & 0.053 & 0.038 & 0.001 & 0.001 & 0.001 & 0.210 & 0.070 \\
\hline Concentrate & 0.070 & 0.123 & 0.029 & 0.060 & 0.015 & 0.001 & 0.001 & 0.002 & 0.050 & 0.152 \\
\hline
\end{tabular}

A conventional Japanese Permeability Unit (JPU), as shown in Equation (2), was used to determine the permeability of mixtures:

$$
J P U=\frac{F}{A} \times\left(\frac{L}{\Delta p}\right)^{0.6}
$$

where $F$-air volume $\left[\mathrm{m}^{3} / \mathrm{min}\right] ; A$-suction area $\left[\mathrm{m}^{2}\right] ; L$ - height of layer $[\mathrm{m}] ; \Delta p$-underpressure [mm $\left.\mathrm{H}_{2} \mathrm{O}\right]$. 
The produced $\mathrm{Fe}$ agglomerates had $\mathrm{Fe}_{\mathrm{TO}}$ content within the interval of about $51-54 \mathrm{wt} \%$. Chemical analysis of the samples was determined using XRF spectrometer ARL 9900S (Thermo Fisher Scientific, Waltham, MA, USA). The simultaneous TG-DTA apparatus (Derivatograph-C/PC, MOM Service Co. Ltd., Budapest, Hungary) was used to study the thermal behavior of individual fuels. The minerals species were detected using an SEIFERT XRD 3003/PTS diffractometer (General Electric Company, Boston, MA, USA). Besides the methodologies applied by default, new specific methodologies were implemented as well, which were not commonly used to characterize the materials for the agglomeration process in the world. It referred to the methodologies of the Raman and infrared spectroscopy that facilitate the observation of a substance structure. The studied samples were analyzed in the fields of both spectra. The attenuated total reflection (ATR) method with an infrared microscope based on the Fourier-transform infrared spectroscopy (FTIR) method was used to measure the infrared spectra. The measurements were performed using the NICOLET 6700 FT spectrometer (Thermo Fisher Scientific, Waltham, MA, USA) with a module for the Raman spectra (NXR FT RAMAN ACCESSORY MODULE) and the Standard OMNIC PROFESSIONAL 7 software package (Thermo Fisher Scientific, Waltham, MA, USA).

\section{Results and Discussion}

\subsection{Material Research of Coke and Lignin}

The methodologies of the Raman and infrared spectroscopy were applied to study the structure of carbonaceous matter based on the biomass as well as the standard agglomeration coke. The Raman and infrared spectra provide information about the vibrational and rotational motion of polyatomic particles, where the frequency of vibrational modes depends on the weight of the present atoms and the binding capacity or parameters describing the structure of a molecule. Even though the vibrational frequencies are independent on the infrared (IR) or Raman spectroscopy, the intensities of spectral lines vary. It is so because the intensity for the IR spectrum is proportional to the square root of the dipole moment change, while the intensity of the band for the Raman spectrum is proportional to the square root of the polarizability change during the vibrational motion. Therefore, both methods appropriately supplement each other, as there are relatively intensive bands for the vibrations of polar groups in the IR spectra (with a significant dipole moment change), and the Raman spectra show strong intensity for symmetric vibrations. It follows from the above that vibrational bands are observed by both methods for the molecules characterized solely by the feature of symmetry (low symmetry molecules). A so-called alternative prohibition rule applies to high-symmetry molecules where the total symmetric vibrations are active in the Raman spectrum and inactive in the IR spectrum, and by contrast, the molecules with a center of symmetry are visible in the IR spectra.

Samples of coke showed no IR spectra, which is apparently related to the amorphous structure. The combustion of biomass depends mainly on the carbon structure of the cellulose, hemicellulose, and lignin, which are different from the amorphous structure of the carbon in coke. Their Raman spectra have two distinctive peaks with the maximums at the wave numbers 1310 and $1597 \mathrm{~cm}^{-1}$. These bands can be attributed to the structure of diamond " $\mathrm{D}$ " and graphite " $\mathrm{G}$ " [15]. The $\mathrm{G}$ band originates from vibrations on graphene planes of carbon $\mathrm{sp}^{2}$ atoms hybridization in aromatic structures. It becomes more intensive and sharper for the aromatic structures with a more complete arrangement as the degree of graphitization increases [16,17]. The D band, typically observed at $1350 \mathrm{~cm}^{-1}$, is characteristic of impaired graphene structures of carbon $\mathrm{sp}^{3}$ hybridization, which is peculiar to the diamond structure. This defect is caused by the presence of microcrystalline and turbostratic structures that differ from the graphite structure considerably. It may also result from the presence of basal planes and/or heteroatoms, e.g., $\mathrm{O}, \mathrm{N}, \mathrm{S}$, etc. Both the intensity and the width of the D band increase in relation to the $\mathrm{G}$ band as the carbon structures become more disordered. The comparison of biomass sample spectra also shows that they contained aromatized hydrocarbons, alkanes, lignin, and cellulose at various intensities and overlaps, as shown in Figure 6. 


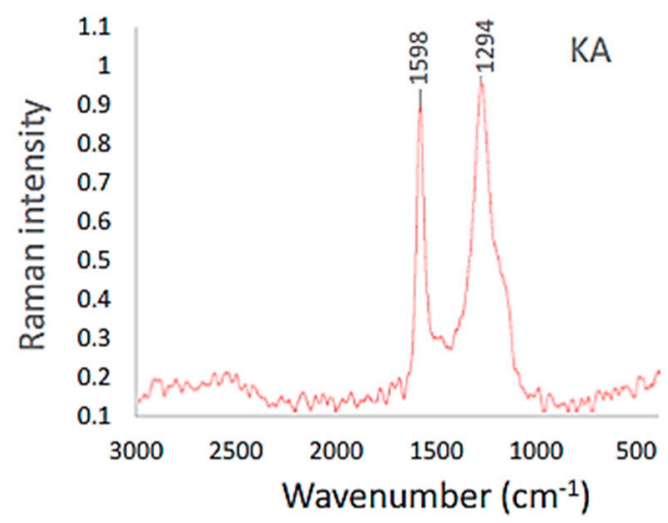

(a)

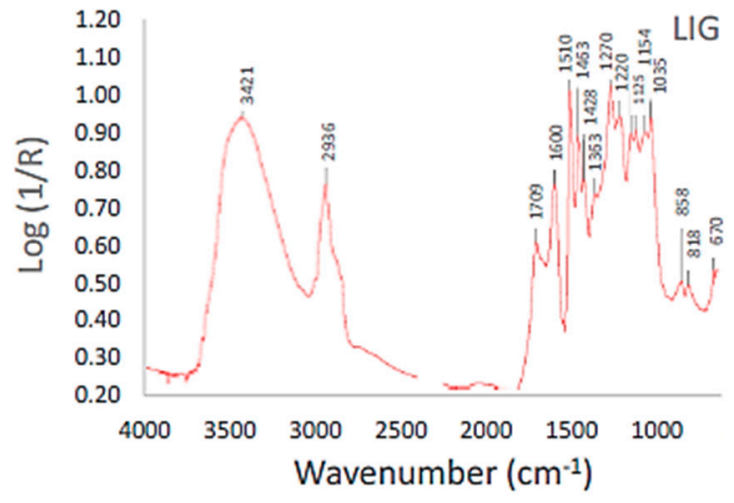

(b)

Figure 6. Raman and infrared spectra of coke breeze (a) and lignin (b).

The course of thermogravimetric analysis for the studied lignin pellets is shown in Figure 7. Based on individual courses of weight loss and respective thermal effect, an endothermic effect was observed in the first double step of thermal stress up to the temperature of $180^{\circ} \mathrm{C}$, corresponding to the evaporation of physically bound water and present low volatile components in the range of $140-180^{\circ} \mathrm{C}$. The weight loss was $8 \%$ in this step, which is within the limits of the set moisture. The following weight loss corresponds to the burning and the release of volatile components of the combustible in the pellets. The initiation temperature was determined to be $276^{\circ} \mathrm{C}$, and the first peak of DTG (differential thermogravimetric) curve was observed at $321^{\circ} \mathrm{C}$. The temperature of BOT (burn out temperature) was determined to be $368^{\circ} \mathrm{C}$ in this step. In the next step, the burning of volatile components is accompanied with two low peaks up to $420^{\circ} \mathrm{C}$ in the DTG record. As the sample heating temperature increases, the exothermic effect of fixed carbon burning begins to show with two maximums, namely at 701 and $742{ }^{\circ} \mathrm{C}$. The burning process in these consecutive steps starts at the initiation temperature of $666^{\circ} \mathrm{C}$ and ends at $751^{\circ} \mathrm{C}$. The maximum reaction rate for this zone of fixed carbon burning was determined to be $4.3 \% \mathrm{~min}^{-1}$ at the temperature of $742{ }^{\circ} \mathrm{C}$.

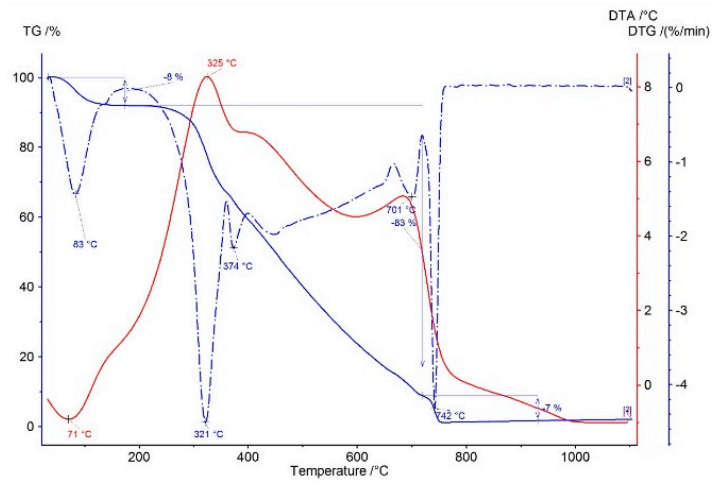

(a)

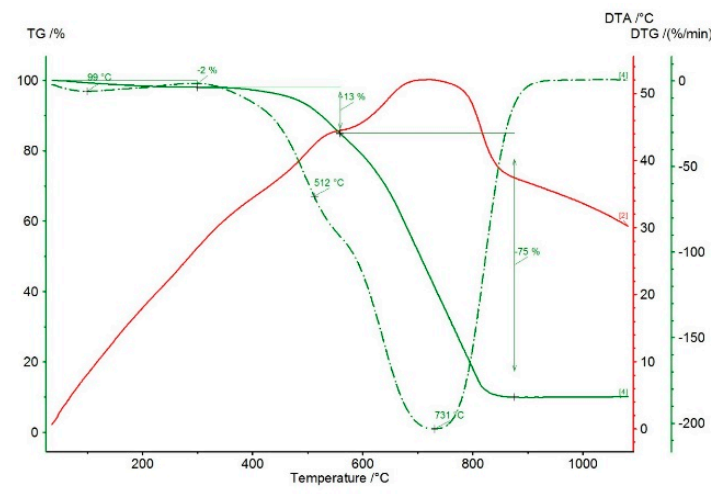

(b)

Figure 7. Thermogravimetric analysis of lignin pellets (a) and coke breeze (b).

Differences in the temperature ranges of a material release can be seen in the comparison of the TGA (thermogravimetric analysis) record for lignin pellets and coke powder. Coke showed an intensive weight loss due to the burning of fixed carbon, which has the majority representation here. The present constituents of a volatile combustible in coke were released at higher temperatures compared to lingin (LIG) pellets. This was caused by the predominant release of low volatile components from individual types of mixed coal in the production of coke or the carbonization of a coal charge. The differences in TG curves of both measured samples at the same rate of heating in an oxidizing atmosphere confirm 
the higher reactivity of the tested biomass with regard to its structure and composition. The residual content of the matter corresponds to the amount of determined ash content, which is relatively stable up to $1100{ }^{\circ} \mathrm{C}$.

\subsection{Impact of Lignin on the Agglomeration Process}

The substitution of coke in the agglomeration charge with biomass has a marked impact on the pelletizing process. There is little room for an extensive pre-treatment of biomass in the agglomeration process. The basic requirement for the use of biomass is to provide the desired grain size composition. It is not possible to carry out treatment (e.g., a reduction) of crude biomass in the same way as the treatment of coke powder because biomass has a soft fibrous texture. The study of biomass disintegration is related to the requirements for the properties of the agglomixture for the combustion process in the sintered layer. In this respect, it is necessary to address the possibilities of adjusting the granulometry of the biomass and the effect on properties such as mainly the burning rate, the change in the permeability of the agglomixture, and the overall thermal effect of sintering. Grain sizes for the substitution of coke with lignin were optimized based on experiments of burning coke and lignin with various grain sizes. It is apparent that the granulometry of mixed fuels (substitution of coke with lignin) was slightly shifted in terms of a drop in the finest fractions with the increasing substitution of coke with lignin, as shown in Figure 8.

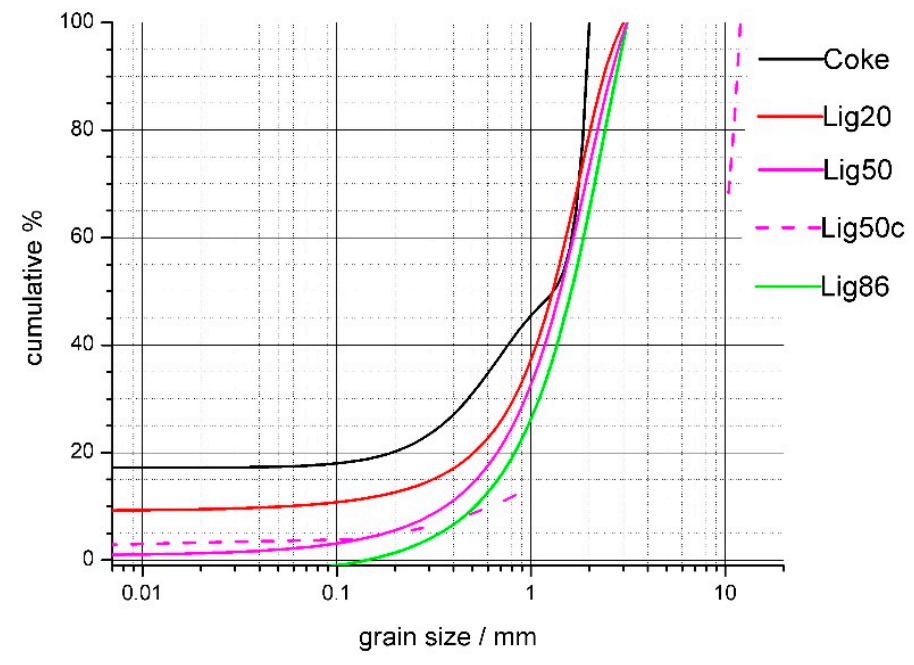

Figure 8. Granulometry curves change after coke substitution with lignin.

The pre-pelletization process may significantly differ from the standard charge with coke fuel, depending on the pelletizing properties of biomass and its wettability. The different densities of the fuels represent another factor affecting the pelletizing process. The increased substitution of coke with biomass has a more significant effect on the bulk density of a charge as well when there is a requirement for an energy substitution of fuel with different calorific volume, which is generally lower in biomass. Figure 9 shows the impact of substitution on both the bulk density of the charge and the permeability. 


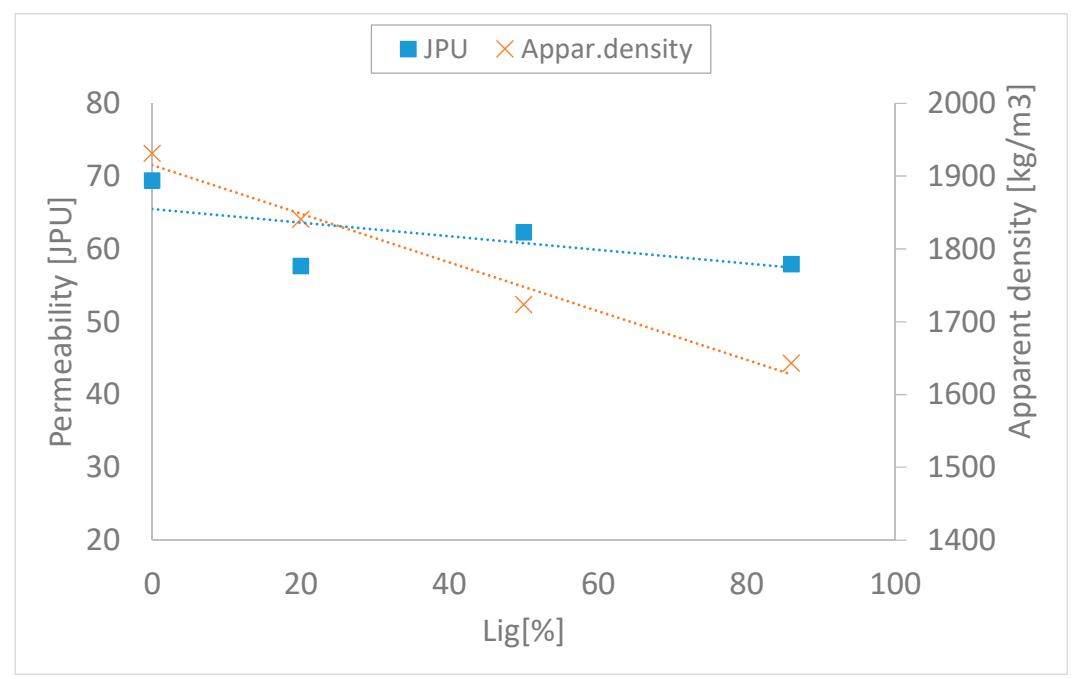

Figure 9. Impact of substitution on both the apparent density of the charge and the permeability.

The quality of a pre-pelletized charge and the share of biofuels in it were also reflected in the very course of charge sintering. An area of temperatures at which melt phases are formed can be analyzed from temperature curves. For this purpose, parameters of a so-called liquid phase formation area (LPFA) and duration of temperature for mineral melting (DTMM) were calculated (3) and (4).

$$
\begin{gathered}
\text { LPFA }=\int_{t_{i}}^{t_{e}}\left(T_{t}-T_{i}\right) d t\left[{ }^{\circ} \mathrm{C} \cdot \mathrm{s}\right] \\
D T M M=t_{e}-t_{i}[\mathrm{~s}]
\end{gathered}
$$

where $t_{e}$-final time for smelting; $t_{i}$-beginning time for smelting; $T_{i}$-initial temperature of melting process; $T_{t}$-temperature in enclosed area.

The temperature curves characterizing the course of temperature change in three horizons of the sintered layer showed various intensities and maximums reached for individual cases. The impact of substitution in terms of both the quantity and the type of biomass is evident and corresponds to the present knowledge from studies of biomass combustion in the conditions of the agglomeration layer. Figure 10 illustrates the course of temperatures without the substitution of coke and with the $20 \%$ substitution of coke with lignin. Areas of temperatures over $1050{ }^{\circ} \mathrm{C}$, as indicated in the graphs, represent the areas or temperature fields where the formation of an agglomeration melt is expected (LPFA-liquid phase formation area in $\left[{ }^{\circ} \mathrm{C} \cdot \mathrm{s}\right]$ ) given the present components of the agglomeration charge. These areas were computed by the integration of a curve within the limits of a time interval for the temperatures over $1050{ }^{\circ} \mathrm{C}$. The said duration of this time interval is expressed as a parameter of the DTMM (duration of temperature for mineral melting in [s]). The substitution of lignin for coke has manifested itself in the reduction of the DTMM and the drop in maximum temperatures, and thus in the decrease in the LPFA as well, as shown in Figure 10b.

The comparison of temperature fields and sintering intensity for various types of biomass (that were analyzed in the previous research papers of the authors) with a constant substitution $(20 \%$ of coke) is shown in Figure 11. Sawdust from pine wood (SDPW) and sawdust from oak wood (SDOW) seem to be the least appropriate types of biomass here (among the tested substitute fuels) due to the observed effect of a non-homogeneous combustion with the degradation of temperature field toward the grate and the significant increase in the sintering time caused mainly by the decreased permeability and instability of the charge. The opposite extreme of an intensive course of the thermal change in the agglomeration layer was seen in case of sintering with hemp shives (HS), where the shortest sintering time was measured, while there was an overlapping of thermal waves. 


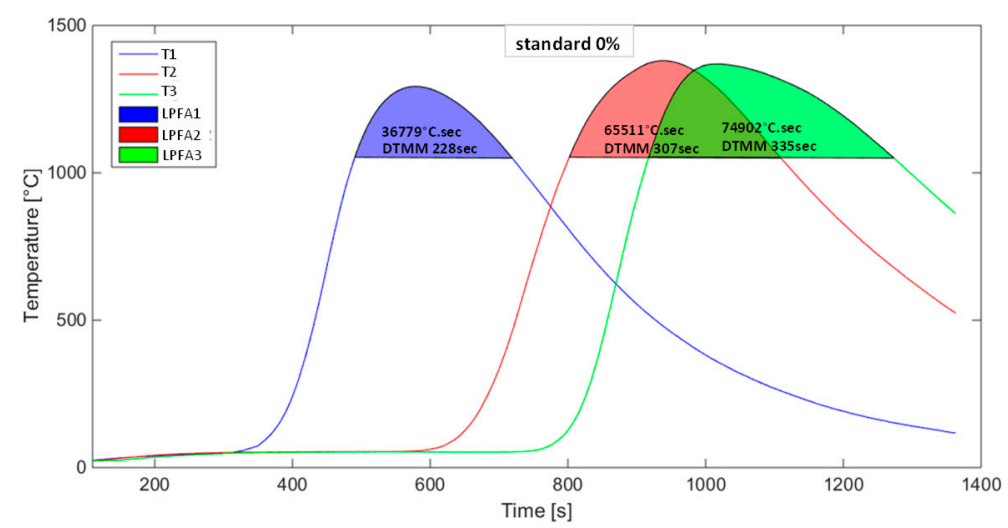

(a)

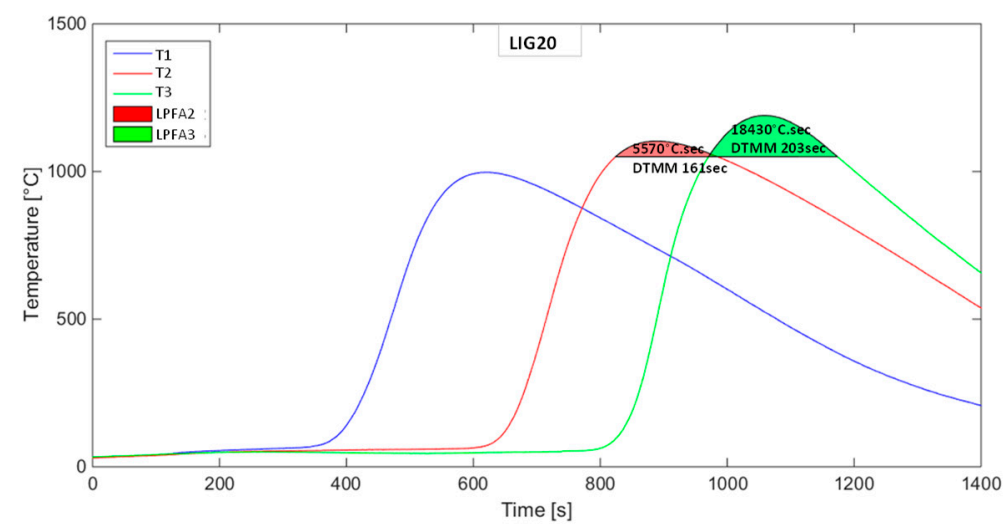

(b)

Figure 10. Temperature curves in measured horizons of the sintered layer: (a) without coke substitution,

(b) $20 \%$ of coke substitution with lignin.

Figure 12 shows the comparison of maximum temperatures in three horizons of the sintered layer and in the flue gas stream, as well as the total sintering time using various substitutions of coke with lignin. The maximum temperatures in the agglomeration layer decreased as the share of the substitute biomass increased, while the sintering time shortened as well. In general, biomass fuels burn more quickly than coke powder due to their high porosity and reaction surface, resulting in an increase in the vertical sintering rate. Lower temperatures in the sintered layer observed with the addition of lignin can also be attributed to the condensation of semi-volatile and volatile organic compounds. These compounds can reduce the heat transfer in the direction of burning, as the case may be.

Agglomerates with minor variations in the chemical and mineralogical composition were formed using lignin with up to $50 \%$ substitution of coke [18]. The content of $\mathrm{Fe}_{\text {TOT }}$ in the agglomerates was $53-54 \mathrm{wt} \%$ at the basicity of 1.7-1.8. In terms of mineralogical composition, the agglomerates consisted of four major phases: iron oxides (40-60 wt\%), ferrites (20-30 wt \%, most of which were complex compounds of silicoferrites of calcium and aluminium (SFCA)), glass $(<10 \mathrm{wt} \%)$, and calcium silicates $(<10 \mathrm{wt} \%)$. 

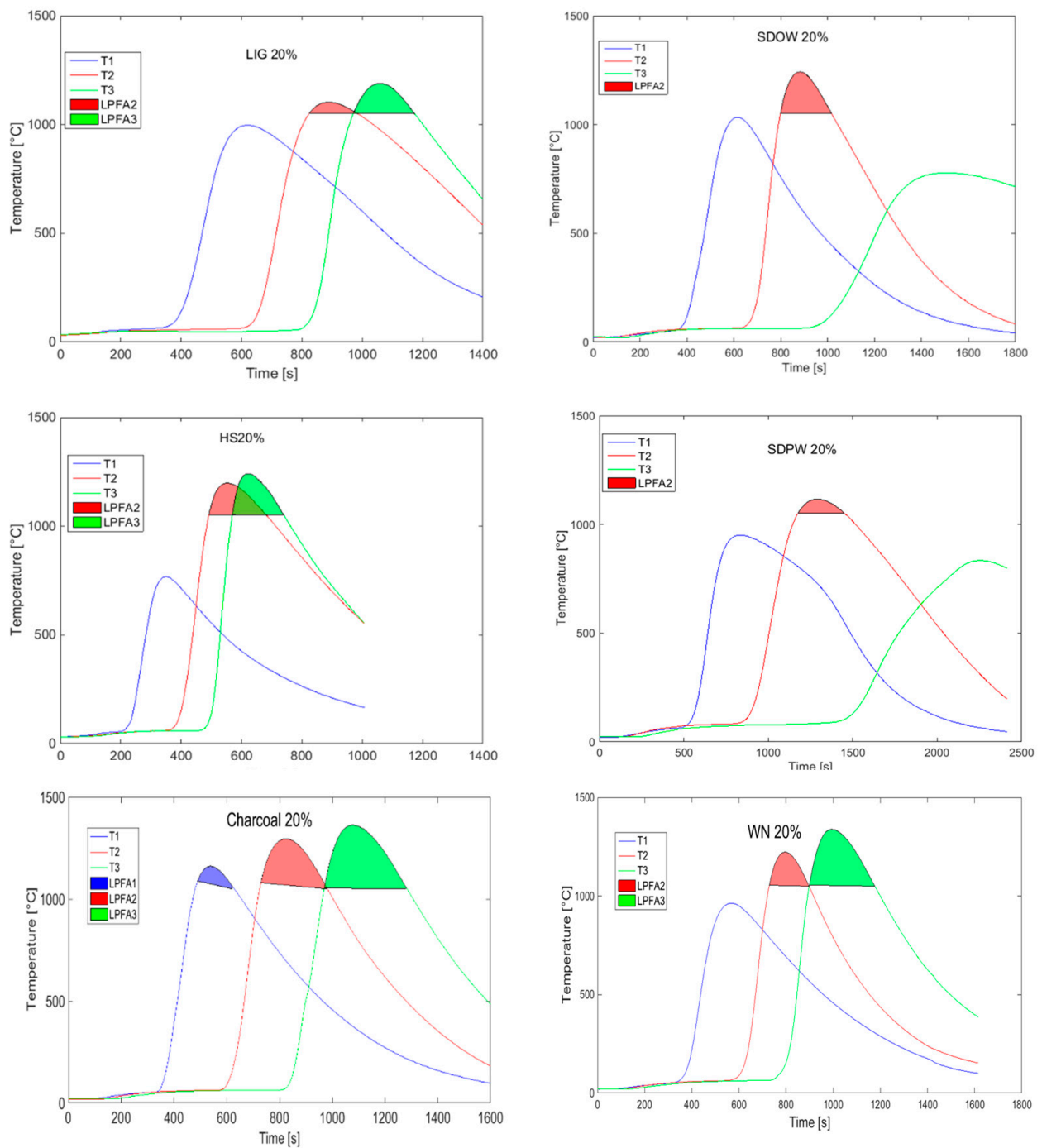

Figure 11. Temperature curves for $20 \%$ coke substitution with biomass. (WN: walnut shells, Charcoal, Lig: lignin, SDOW: saw dust from oak wood, SDPQ: saw dust from pine wood, HS: hemp shoves.).

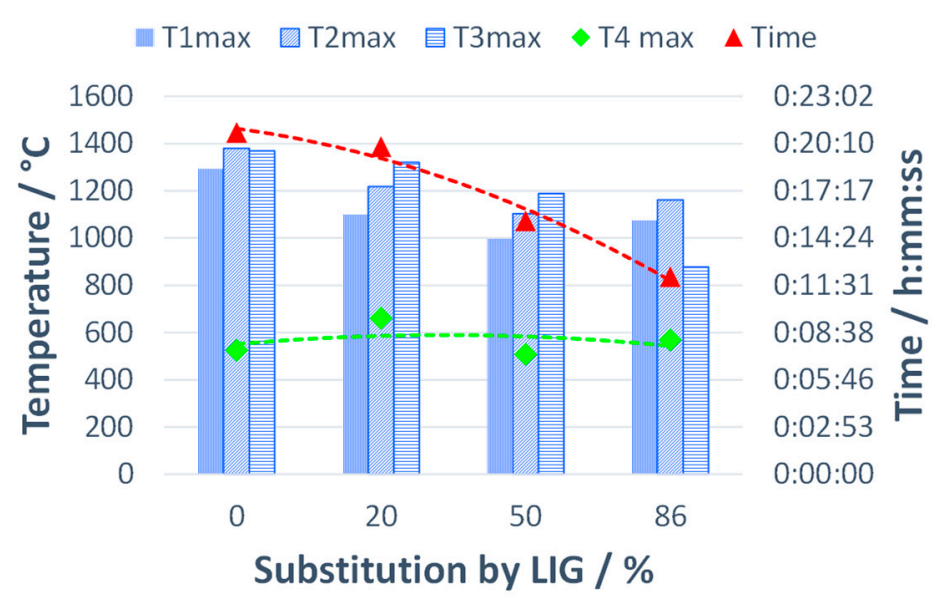

Figure 12. Impact of coke substitution with lignin on maximum temperatures and sintering time.

The performance parameters of sintering were determined based on the course of sintering, which is also confirmed by Figure 13 below. The substitution of lignin for coke up to $50 \%$ was 
reflected in the increase in production parameters, primarily due to the higher vertical sintering rate. The calculation of the sintering rate takes into account different parameters for various research projects. It has also been determined that the heat wave moves through a bed with approximately constant velocity, $v[19]$. This constant velocity, $v$, is expressed as:

$$
v=\frac{h}{S T}
$$

where $h$ is the thickness of the sinter bed, and $S T$ is the sintering time.

The paper [20] describes the sintering velocity using the following equation:

$$
v=\frac{h_{g} \times W}{h_{s} \times(1-f)}
$$

where $h_{g}$ is the heat capacity of the gas; $h_{s}$ is the heat capacity of the solid; $W$ is the normal volume of the fluid/unit cross-section of the bed/minutes; and $\mathrm{f}$ is the voids fraction/unit volume of the bed.

The sintering rate can be also expressed by the rate of thermal wave propagation (7), which depends on the volumetric flow rate of air sucked through the layer and the actual thermal capacity of gas and solid components. For this reason, the permeability of agglomeration charge is the key to the high sintering rate. A temperature profile, formed throughout the height of the sintered layer, has a substantial effect on both the type of produced agglomerate and its physical and reduction properties:

$$
v_{S}=\frac{w_{g} \times \rho_{g} \times c_{g}}{(1-\varepsilon) \times \rho_{f} \times c_{f}}
$$

where $v_{s}$-sintering velocity; $w_{g}$-volumetric flow rate of gas; $\rho_{g}$-density of gas; $\rho_{f}$-density of mixture; $c_{g}$-thermal capacity of gas; $c_{f}$-thermal capacity of mixture; and $\varepsilon$ - permeability.

The vertical rate was calculated on the basis of (8):

$$
v_{S}=\frac{P r}{k_{A} \times \rho \times k_{P r} \times V} \times 1000
$$

where $P r$-specific production; $k_{A}$-conversion coefficient; $\rho$-apparent density of mixture; $k_{P r}$-production coefficient; $V$-sintered volume.

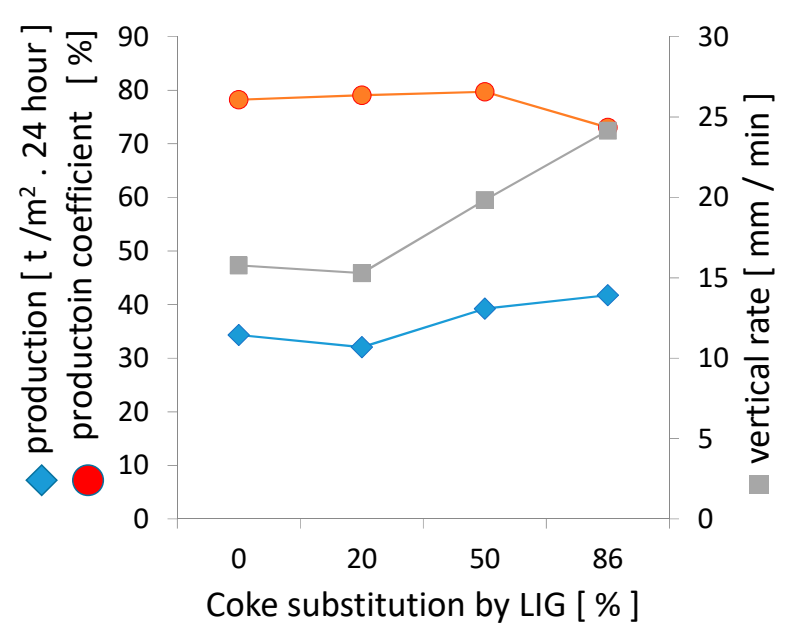

Figure 13. The impact of coke substitution with lignin on the production parameters.

The impact of coke powder substitution with lignin on the granulometric and strength parameters of the agglomerate shows certain differences, as shown in Figure 14. It is clear based on the analysis of the grain size distribution that better parameters were achieved with up to a $50 \%$ substitution of 
lignin for coke against the standard sintering without the substitution of coke powder. In a series of sinterings with modified lignin pellets, the agglomerate even showed an abrasion that was lower by ca. $1.5 \%$ at up to a $20 \%$ substitution of coke, which was manifested in the strength of the agglomerate as well. In the case of $50 \%$ substitution of coke with lignin, this positive effect persisted, but further increase in the substitution coefficient was already negatively reflected in the strength properties as well. Here, it is necessary to realize the effect of increased substitution on the bulk density and the yield of agglomerates in particular.

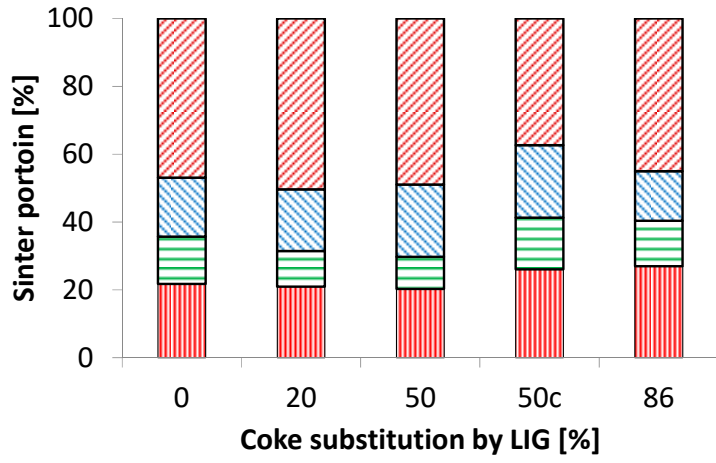

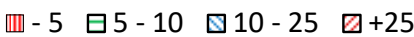

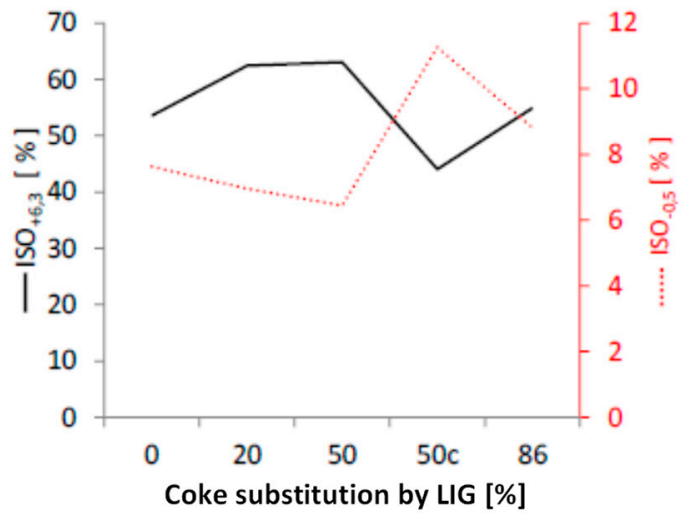

(b)

Figure 14. The impact of coke substitution on the granulometric (a) and strength parameters (b) of the agglomerates.

Agglomerates produced with the substitution of modified lignin pellets for coke showed a different nature as well, where a more fine-grained and heterogeneous porous structure was observed. The size of pores in the produced agglomerate (and the total agglomerate porosity at the substitution of up to $50 \%$ ) increased as the substitution level was raised, as shown in Figure 15.

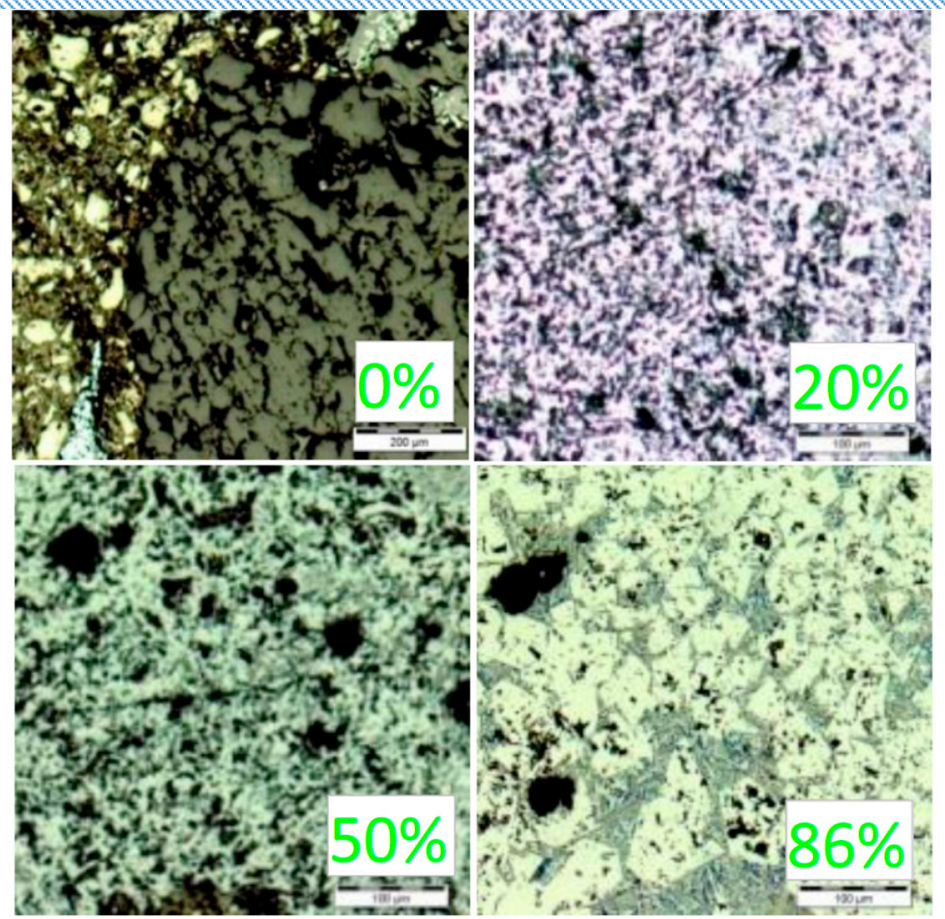

Figure 15. Microstructure of sinters with coke substitution by lignin. 
The rise in porosity is probably associated with the rise in the volumetric proportion of biofuel in the mixture and the kinetics of its combustion, where the increased rate of lignin combustion and its quantity create the preconditions for the increased porosity. It may also positively affect the resulting reducibility of agglomerate with the substitution of modified lignin pellets for coke, since such agglomerates may have higher reducibility as well [21]. The temperature profiles that became more downward as the substitution of coke increased constituted a relevant factor as well. At $86 \%$ substitution of coke, this effect was manifested more significantly along with the structure of original ore grains covered with a small proportion of the melt phase. The predominant part of agglomerate was characterized by the transition of sintered grains to the plastic state, i.e., to the area of softening. It is clear from the results that there was no marked change in the phase composition, i.e., no formation of new phases, at $20 \%$ and $50 \%$ substitution of agglomeration coke with lignin. The share of individual phases changed significantly. At $20 \%$ and $50 \%$ substitution, there is a decrease in the majority of oxide phases (magnetite and hematite) and increase in the bonding phases represented by silicoferrites (SFCA-1 and SFCA) and silicates (larnite and hedenbergite) [18].

The emission profile of sintering with the addition of lignin varied depending on the amount of coke replacement, where a difference in the amount and course of gaseous component formation was observed during the sintering of agglomerate. The use of modified lignin pellets (LIG) for a partial substitution contributed to the increase in carbon oxides, where higher average concentrations were measured and higher specific amounts were calculated against the standard, as shown in Figure 16a. Carbon dioxide is the main reaction product in the combustion of all carbonaceous fuels, and its emissions are directly proportional to the content of carbon in these fuels. It is released into the atmosphere not only in the reaction of carbon and oxygen during the combustion of different types of biomass but also in the combustion of carbon monoxide or organic matter, e.g., methane. In the sintering using lignin, a higher amount of $\mathrm{H}_{2} \mathrm{O}(\mathrm{g})$ should be theoretically present in the gas phase, and due to the lower carbon content in the lignin, the amount of $\mathrm{CO}_{2}(\mathrm{~g})$ should be lower as well. The rise in $\mathrm{CO}_{2}$ at the substitution of coke with lignin can be explained by the raised amount of carbon in the agglomeration process due to the increase in the total amount of fuel (coke + lignin) for individual substitutions, because lignin has a considerably lower calorific value. In sintering without the coke substitution, $4.35 \mathrm{~kg}$ of coke were used. At $20 \%$ substitution of coke with lignin, $5.52 \mathrm{~kg}$ of fuel (coke + lignin) were used, and $7.34 \mathrm{~kg}$ of fuel were used at $50 \%$ substitution of coke with lignin. However, the total amount of $\mathrm{CO}_{2}$ is also affected by other factors-e.g., sintering time, amount of gas phase, temperature in the sintered layer, mechanism of carbon combustion, etc. In the future, the $\mathrm{CO}_{2}$ emissions in the production using lignin can be reduced by optimizing the conditions of charge preparation and its sintering. However, its overall positive aspect is the reduction of carbon footprint in the agglomeration process as a result of the so-called zero $\mathrm{CO}_{2}$ balance in the formation and processing of the lignin. The change in $\mathrm{NO}_{X}$ concentration during sintering with the substitution of lignin for coke copies the profile and the course of $\mathrm{CO}_{2}$ curves, and it is also connected with the change in the concentration of oxygen during sintering. Overall, the substitution of coke with lignin reduces the content of $\mathrm{NO}_{X}$, as shown in Figure $16 \mathrm{~b}$. As a consequence of the significantly lower content of sulfur in the lignin, lower emissions of $\mathrm{SO}_{\mathrm{x}}$ were found in the flue gas when coke had been substituted with lignin. 


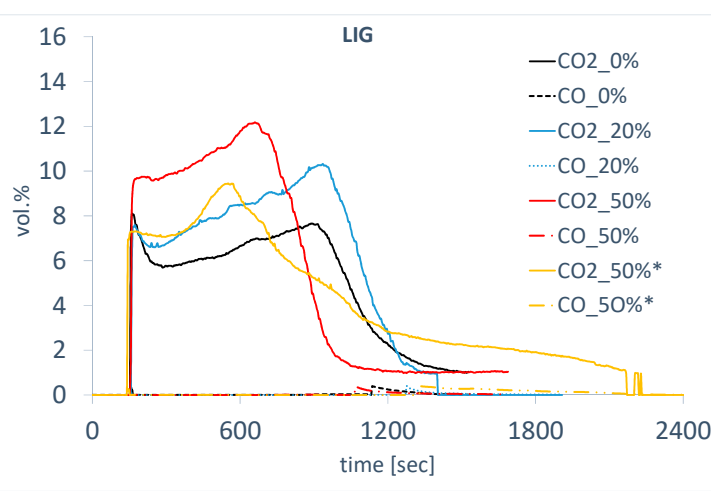

(a)

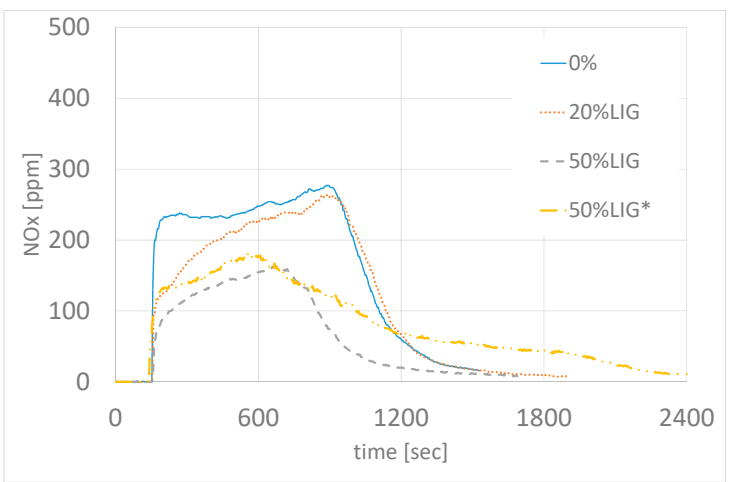

(b)

Figure 16. Concentration of $\mathrm{CO}, \mathrm{CO}_{2},(\mathbf{a})$ and $\mathrm{NO}_{\mathrm{x}}(\mathbf{b})$ through the sintering with coke substitution. (* granulometry of Lig50c).

\section{Conclusions}

Today, the attention of the laboratory agglomerate research is focused on the substitution of conventional fossil fuel with biomass. Theoretical studies of various types of biomass in terms of their properties, as well as their possible utilization, provide a sound basis for the selection of suitable types for use and application in the agglomeration process. The tested lignin pellets seem to be even more appropriate, as they show a higher energy potential than, for instance, conventionally compacted (pressed) dendromass with regard to the technological process of wood mass hydrolyzation. The lignin has high reactivity, low content of ash, and low content of sulfur. The experiments confirm the higher reactivity of the tested lignin with regard to its structure and composition. The combustion of lignin biomass depends mainly on the carbon structure of the cellulose and hemicellulose, which are different from the amorphous structure of the carbon in coke. The residual content of the matter corresponds to the amount of determined ash content, which is relatively stable up to $1100{ }^{\circ} \mathrm{C}$. Increased substitution of coke with lignin has a more significant effect on the bulk density of a charge as well when there is a requirement for energy substitution of fuel with different calorific volume, which is generally lower in lignin biomass. The substitution of lignin for coke has manifested itself in the reduction of the duration of temperature for mineral melting and the drop in maximum temperatures, and thus in the decrease in the liquid phase formation area as well. The substitution of lignin for coke up to $50 \%$ was reflected in the increase in production parameters, which is primarily due to the higher vertical sintering rate. Agglomerates produced with the substitution of modified lignin pellets for coke showed a different nature as well, where a more fine-grained and heterogeneous porous structure was observed. Based on the laboratory research of lignin, it is possible to predict its standard properties (chemical and mineralogical composition, physical and mechanical properties) and improvement of certain technological and ecological parameters (e.g., increase in the productivity and reduction of sulfur and nitrogen oxides) for the production of the agglomerate. Therefore, its utilization in the agglomeration process is very prospective.

In conclusion, we can say that lignin has proven to be a suitable alternative fuel in the agglomeration process.

Author Contributions: Experimental analysis, R.F., J.L., M.F., G.F. and M.D.; investigation, conceptualization, writing original draft preparation, writing review and editing, R.F.; results, formal analysis, M.F.; investigation, validation, J.L. and G.F.; visualization, project administration, M.D. All authors have read and agreed to the published version of the manuscript.

Funding: This research was funded by [APVV] Slovak Research and Development Agency, Slovak Republic number APVV-16-0513.

Conflicts of Interest: The authors declare no conflict of interest. 


\section{References}

1. Findorák, R.; Frőhlichová, M.; Legemza, J. Biomasa v Aglomeračnom Procese; Technical University of Košice: Košice, Slovakia, 2020; ISBN 978-80-553-3567-4.

2. Shengwei, T.; Xilou, D.; Kai, Z. Study on the craft technology scheme of the sinter flue gas desulphurization of Ma'anshan. In Metal World; Iron \& Steel Co. Ltd.: Xi'an, China, 2008; Volume 6, pp. 20-23.

3. Legemza, J.; Frohlichova, M.; Findorak, R. The process of simulating the agglomerate laboratory production under laboratory conditions. Acta Metall. Slov. 2010, 1, 70-75.

4. Murakami, K.; Sugawara, K.; Kawaguchi, T. Analysis of combustion rate of various carbon materials for iron ore sintering process. ISIJ Int. 2013, 53, 1580-1587. [CrossRef]

5. Lovel, R.; Vining, K.; Dell'Amico, M. Iron ore sintering with charcoal. Min. Process. Extractr. Metall. 2007, 116, 85-92. [CrossRef]

6. Kawaguchi, T.; Hara, M. Utilization of biomass for iron ore sintering. ISIJ Int. 2013, 53, 1599-1606. [CrossRef]

7. Fan, X.; Ji, Z.; Gan, M.; Chen, X.; Li, W.; Yu, Z. Strengthening refractory iron ore sintering with biomass fuel. In Proceedings of the 3rd International Symposium on High-Temperature Metallurgical Processing-TSM 2012, Orlando, FL, USA, 3 April 2012; pp. 357-364.

8. Gan, M.; Fan, X.; Chen, X.; Ji, Z.; Lv, W.; Wang, Y.; Yu, Z.; Jiang, T. Reduction of pollutant emission in iron ore sintering process by applying biomass fuels. ISIJ Int. 2012, 52, 1574-1578. [CrossRef]

9. Findorák, R.; Fröhlichová, M.; Legemza, J. The effect of charcoal addition on iron-ore sintering performance. In Proceedings of the 13th International Multidisciplinary Scientific Geoconference SGEM, Albena, Bulgaria, 16-22 June 2013; Volume 2, pp. 637-642.

10. Mašlejová, A. Evaluation of iron ore sinter structure using a various types of biomass. In Proceedings of the 13th SGEM GeoConference on Science and Technologies, Albena, Bulgaria, 16-22 June 2013; Volume 2, pp. 581-588.

11. Frőhlichová, M.; Findorák, R.; Legemza, J.; Džupková, M. The fusion characteristics of ashes from lignin and the coke breeze. Arch. Metall. Mater. 2018, 3, 1523-1530.

12. Legemza, J.; Frőhlichová, M.; Findorák, R.; Džupková, M. Modelling of mass and thermal balance and simulation of iron sintering process with biomass. Metals 2019, 9, 1010. [CrossRef]

13. Findorak, R.; Frohlichova, M.; Legemza, J.; Dzupkova, M. Utilization of Infrared Thermometry for Analyse of Biomass Burning Process. In Proceedings of the International Multidisciplinary Scientific GeoConference: SGEM: Surveying Geology \& Mining Ecology Management, Albena, Bulgaria, 30 June-9 July 2018; Volume 18, pp. 1017-1022.

14. Majerčák, Š.; Majerčáková, A. Vysokopecná Vsádzka; ALFA Bratislava: Bratislava, Slovakia, 1986.

15. Kruk, M.; Kohlhaas, K.M.; Dufour, B.; Celer, E.B.; Jaroniec, M.; Matyjaszewski, K.; Ruoff, R.S.; Kowalewski, T. Partially graphitic, high-surface-area mesoporous carbons from polyacrylonitrile templated by ordered and disordered mesoporous silicas. Microporous Mesoporous Mater. 2007, 102, 178-187. [CrossRef]

16. Sadezky, A.; Muckenhuber, H.; Grothe, H.; Niessner, R.; Pöschl, U. Raman microspectroscopy of soot and related carbonaceous materials: Spectral analysis and structural information. Carbon 2005, 43, 1731-1742. [CrossRef]

17. Koizumi, N.; Urabe, Y.; Inamura, K.; Itoh, T.; Yamada, M. Investigation of carbonaceous compounds deposited on NiMo catalyst used for ultra-deep hydrodesulfurization of gas oil by means of temperature-programmed oxidation and Raman spectroscopy. Catal. Today 2005, 106, 211-218. [CrossRef]

18. Fröhlichová, M.; Findorák, R.; Legemza, J.; Džupková, M. Impact of substituting coke with biomass on the mineralogical composition of the iron ore agglomerate. Metals 2020, 10, 909. [CrossRef]

19. Yang, W.; Ryu, C.; Choi, E.S. Modelling of combustion and heat transfer in an iron ore sintering bed with considerations of multiple solid phases. ISIJ Int. 2004, 44, 492-499. [CrossRef]

20. Blaskett, D.R. The sintering symposium, Port Pirie. Aust. Inst. Min. Metall. 1960, 66, 61-70.

21. Jursova, S.; Pustejovska, P.; Brozova, S. Study on reducibility and porosity of metallurgical sinter. Alex. Eng. J. 2018, 57, 1657-1664. [CrossRef]

(C) 2020 by the authors. Licensee MDPI, Basel, Switzerland. This article is an open access article distributed under the terms and conditions of the Creative Commons Attribution (CC BY) license (http://creativecommons.org/licenses/by/4.0/). 